
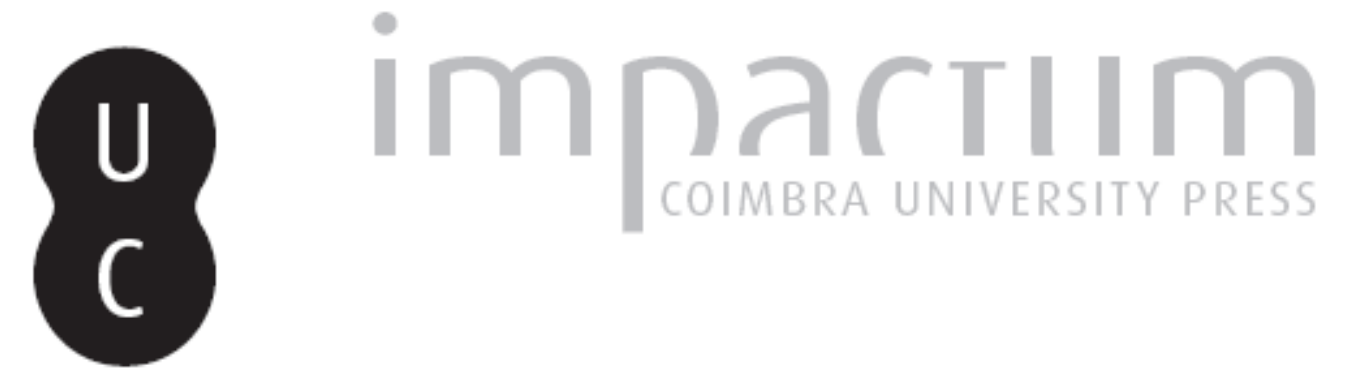

Max Weber e o debate sobre a natureza da economia antiga

Autor(es): $\quad$ Tabone, Danilo Andrade

Publicado por: Annablume Clássica; Imprensa da Universidade de Coimbra

URL persistente:

URI:http://hdl.handle.net/10316.2/24340

DOI:

DOI:http://dx.doi.org/10.14195/1984-249X_8_5

Accessed : $\quad$ 26-Apr-2023 13:00:43

A navegação consulta e descarregamento dos títulos inseridos nas Bibliotecas Digitais UC Digitalis, UC Pombalina e UC Impactum, pressupõem a aceitação plena e sem reservas dos Termos e Condições de Uso destas Bibliotecas Digitais, disponíveis em https://digitalis.uc.pt/pt-pt/termos.

Conforme exposto nos referidos Termos e Condições de Uso, o descarregamento de títulos de acesso restrito requer uma licença válida de autorização devendo o utilizador aceder ao(s) documento(s) a partir de um endereço de IP da instituição detentora da supramencionada licença.

Ao utilizador é apenas permitido o descarregamento para uso pessoal, pelo que o emprego do(s) título(s) descarregado(s) para outro fim, designadamente comercial, carece de autorização do respetivo autor ou editor da obra.

Na medida em que todas as obras da UC Digitalis se encontram protegidas pelo Código do Direito de Autor e Direitos Conexos e demais legislação aplicável, toda a cópia, parcial ou total, deste documento, nos casos em que é legalmente admitida, deverá conter ou fazer-se acompanhar por este aviso. 
jan.2012

issn $2179-4960$

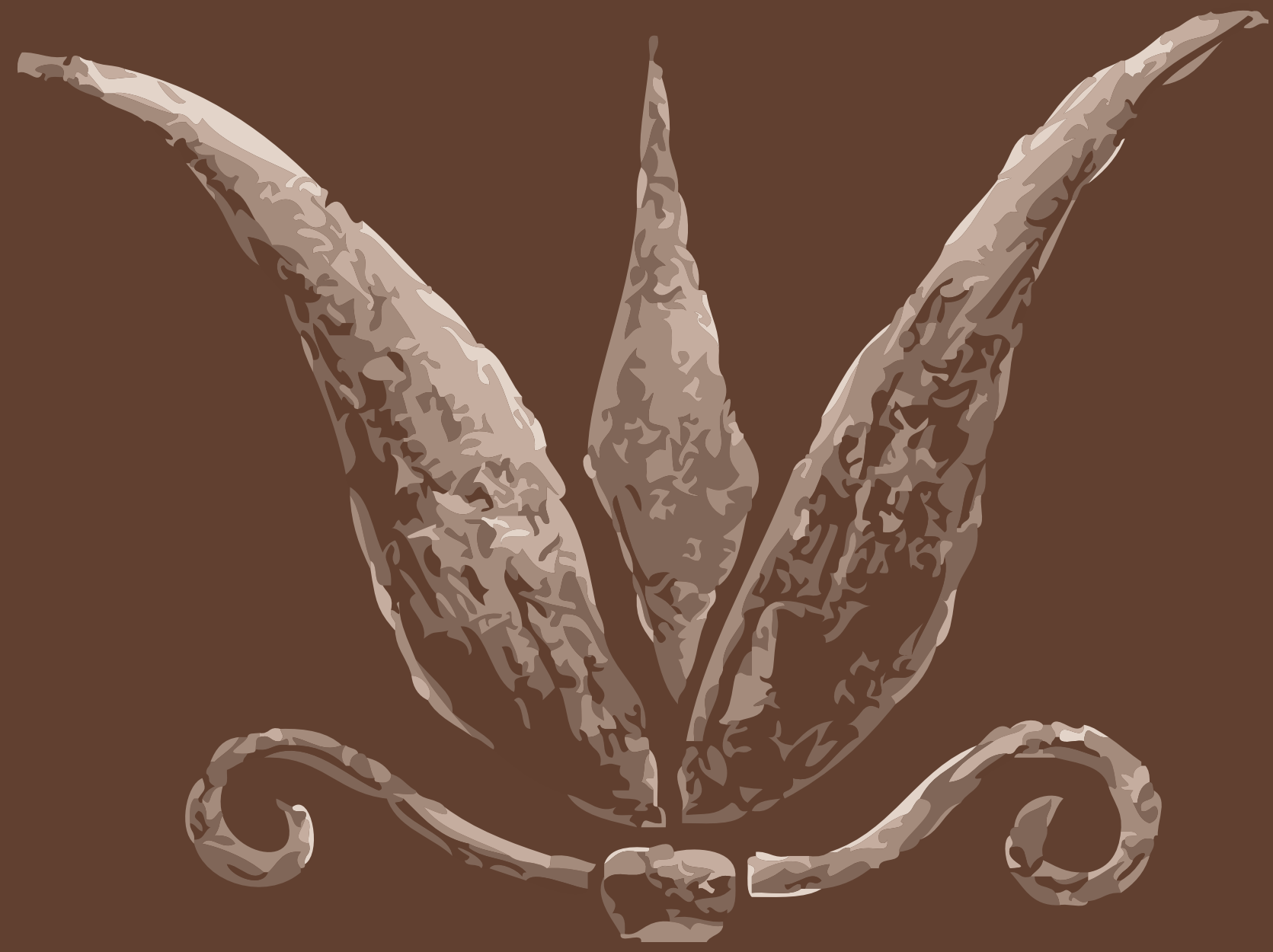

R E V I S T A
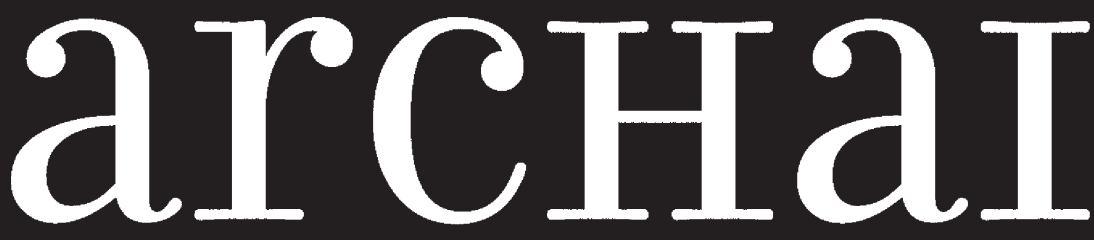

AS ORIGENS DO PENSAMENTO OCIDENTAL

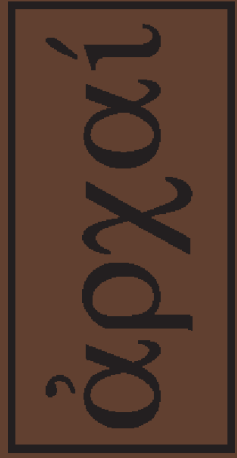

ARCHAI JOURNAL: ON THE ORIGINS OF WESTERN THOUGHT
arcHaI

AS ORIGENS DO PENSAMENTO OCIDENTA.

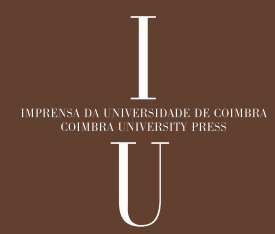

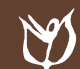




\section{MAX WEBER E 0 DEBATE SOBRE A NATUREZA DA ECONOMIA ANTIGA}

TABONE, D. A. (2012). “Max Weber e o debate sobre a natureza da economia antiga". Archai n. 8, jan-jun 2012, pp. 47-52.

RESUMO: Surgiu, no final do século XIX e entrando no século XX, um debate nos meios acadêmicos alemães sobre a natureza da economia antiga, o debate entre "primitivistas", representados por Karl Bücher, e "modernistas", representados por Eduard Meyer. Também Max Weber tomou parte nestas discussões marcando a historiografia sobre o tema. Considerar-se-á aqui o debate como um todo, e, em específico as posições de Weber.

PALAVRAS-CHAVE: Historiografia; economia antiga; história econômica; Max Weber;

ABSTRACT: In the end of the nineteenth century and well into the twentieh century there happened a debate in German academic cricles about the nature of ancient economy, the debate between "primitivists", represented by Karl Bücher, and "modernists", represented by Eduard Meyer. Max Weber also took part in these discussions marking the historiography on the subject. The debate as a whole will be considered here, and in particular the positions of Weber.

KEYWORDS: Historiography; ancient economy; economical history; Max Weber.
* Bacharel e Licenciado

em História - UNESP/ Franca - membro do LABECA (MAE-USP). Remeto meus agradecimentos à Profa

Ms. Maria Celeste Fachin Departamento de História UNESP/Franca) pela leitura, assim como pelas correções e sugestões feitas.

1. Fábio Duarte Joly, professor na Universidade Federal do Recôncavo da Bahia (UFRB), doutor em História Econômica pela USP (sob orientação do Prof. Dr. Norberto Guarinello),

pelo qual defendeu a tese Libertate opus est. Escravidão, manumissão e cidadania à época de Nero (54-68 d.C.). Tem como principais obras: $A$ escravidão na Roma antiga: política, economia e cultura

e Tácito e a metáfora da escravidão: um estudo de cultura política romana. Com isto, se pode concluir que Joly transita entre as áreas de economia, sociedade e relações de poder, onde se torna compreensivel 0 artigo, em vista do tema ligado à obra de Max Weber.

6. Karl Wilhelm Bücher (Kirberg 1847 - Leipzig 1930) foi economista, um dos fundadores da "economia

\section{Danilo Andrade Tabone*}

A leitura do artigo do Professor Fábio Duarte Joly ${ }^{1}$ (JOLY, 1999) despertou um interesse acerca de alguns dos temas lá tratados, temas sobre os quais o estudo resultou neste trabalho. 0 artigo de Joly trata da tese de Habilitation de Max Weber, Die römische Agrargeschichte in ihrer Bedeutung für das Staats-und Privatrecht, de 1891. Mas o artigo toca em outros pontos, os quais ele não aprofunda, o que é compreensível por não serem o objetivo principal do artigo, são: o debate sobre a natureza da economia antiga durante o final do século XIX e o início do século XX; a posição de Weber dentro deste referido debate; e a herança do trabalho de Weber nesta área, em especial na obra de um dos maiores herdeiros do pensamento weberiano, o historiador Moses Finley.

Sobre a história econômica, sabe-se que ela é uma descoberta do século XIX, mas não exatamente como um domínio do historiador, senão como uma área do economista. Os economistas alemães os Nationalökonimiker - da Escola Historicista Alemã de Economia - com expoentes como List, Schmoller, Hildebrandt e Sombart elaboraram certo número de teorias atribuindo à vida econômica uma evolução caracterizada por uma sucessão de estágios distintos (WILL, 1954, p. 9). Um desses teóricos, Karl Bücher ${ }^{2}$, apoiado em ideias já desenvolvidas por Karl Rodbertus em $1865^{3}$, distinguiu três estágios suces- 
sivos na evolução econômica: a economia doméstica (Hauswirtschaft ou Oikenwirtschaft, quer dizer, Oikonomia no sentido primeiro do termo, não no sentido aristotélico $^{4}$ ); a economia urbana (Stadtwirtschaft); a economia territorial ou nacional (Volkswirtschaft, que não é bem traduzível). Mas, "a passagem da teoria à história apresentava, evidentemente, dificuldades que Bücher percebeu ele mesmo" (WILL, 1954, p. 9). Assim, ele atribuiu cada um dos estágios à uma grande repartição da história: à Antiguidade a economia doméstica fechada, à Idade Média a economia urbana e à Modernidade a economia nacional. "Pura abstração característica das grandes sínteses do século XIX, o esquema de Bücher não podia resistir ao exame dos factos, sobretudo no que se refere à Antiguidade" (AUSTIN, VIDAL-NAQUET, 1986, p. 16).

Eduard Meyer ${ }^{5}$, típico historiador-filólogo alemão, seguido de outros historiadores alemães como Busolt e Beloch, iniciou a destruição da teoria de Bücher em proveito de uma visão mais "realista" da economia antiga. Para tal transportaram para a antiguidade grega clássica, e mesmo para a arcaica, as condições econômicas da época do capitalismo liberal em que eles viviam. Entretanto, "se a bem dos fatos poderiam provocar uma sã crítica à tese 'primitivista' de Bücher, este estado de espírito 'modernista' exagerou a resposta e conduziu ao excesso oposto" (WILL, 1954 , p. 10). A visão estava contaminada pela visão da economia da Europa moderna do mesmo modo que sua história política grega o estava pela preocupação alemã contemporânea da unidade nacional (AUSTIN, VIDAL-NAQUET, 1986, p. 17).

Segundo a visão modernista, teria havido, desde o século VIII, um desenvolvimento da indústria e do comércio com o florescimento de uma produção e de trocas em estilo capitalista, com o esboço de uma economia monetária; as aristocracias fundiárias eram substituídas por aristocracias do dinheiro. A partir de então a história política era reinterpretada: os Estados gregos passaram a ter motivações econômicas e preocupações comerciais em estilo moderno, como por exemplo, desenvolveu-se a ideia de que " a colonização da época arcaica teria obedecido ao móbil de procurar novos mercados para a indústria das metrópoles, tornada excedentária" (AUSTIN, VIDAL-NAQUET, 1986, p. 113). Inclusive conflitos eram assim interpretados, em termos de combates entre cidades comerciais, como a Guerra do Peloponeso, visto como um conflito de interesses entre Atenas e Mégara, e Atenas e Corinto, e não como uma rivalidade política entre Atenas e Esparta, como julgou Tucídides.

Bücher aceitou o debate, limitado ao âmbito da economia grega. Ele mostrou numerosas falhas na tese dos "modernistas": demonstrou com justiça que a base da concepção modernista é um abuso ou, no mínimo, um uso imprudente das fontes (WILL, 1954, p. 11). Ed. Will reconhece que a resposta de Bücher não teve o eco que mereceu, o que, todavia, não torna aceitável a sua própria tese dos três estágios da economia.

Estes são os dois principais modelos interpretativos da economia antiga neste final do século XIX (JOLY, 1999). E, como se pode perceber, o debate ficou restrito aos círculos intelectuais alemães. Foi uma controvérsia essencialmente alemã que, poucas vezes, teve algum eco em outros países. Citem-se dois artigos da Revue des Annales: um de Louis Gernet, de $1933^{6}$, e o outro de Édouard Will, de 1954, os quais se resumiram em sínteses do debate alemão (DESCAT, 1995). Como bem percebem Michel Austin e Pierre Vidal-Naquet "o debate fora visivelmente mal iniciado" (AUSTIN, VIDAL-NAQUET, 1986, p. 17). 0 erro de ambos era o mesmo, e ele estava nos termos do debate - se a economia antiga era primitiva ou moderna - o que pressupunha uma evolução econômica uni linear. Tratava-se simplesmente de determinar em que ponto da linha estava a economia grega.

A questão de saber se se podia estudar a 'economia' grega isoladamente e a partir de conceitos econômicos criados para o mundo moderno, problema fundamental, nem sequer era posta. Enquanto era de conceitos que se deveria ter começado por discutir, fazia-se de conta que o problema se situava unicamente ao nível dos factos (AUSTIN, VIDAL-NAQUET, 1986, p. 18).

\section{A entrada de Weber no debate}

A reação a essas duas posições extremadas se fez sentir desde o início do século XX, em primeiro lugar com questionamentos de ordem psicológica: a mentalidade econômica dos gregos não era, evidentemente, a mesma que a nossa (WILL, 1954, p. 12), como procurou mostrar A. E. Zimmern. Mas foi Max Weber primitiva" (ou, economia não ligada ao mercado), foi também o fundador do jornalismo como disciplina acadêmica. Estudou na Universidade de Bonn - então na Prússia, sede da História, onde entrou em contato com esta ciência e com os Clássicos antigos, chegou a ter aulas com Arnold Schäffer.

3. Rodbertus desenvolveu o conceito de "economia do oikos". 0s oikos seriam as unidades domésticas autônomas, onde o comércio seria eventual e esporádico (JOLY, 1999)

4. Aristóteles na Política designa por este termo os métodos de aquisição "natural" tanto para cidades quanto para particulares (WILL, 1954, p. 9).

5. Eduard Meyer (Hamburgo 18551930), historiador, estudou na Universidade de Bonn, assim como Bücher, além da Universidade de Leipzig.

6. GERNET, L. Comment caractériser l'économie de la Grèce antique?, Annales, 1933 (2), p. 561-566. 
7. Um dos capítulos da obra quefoi traduzida como (FINLEY, 1989).

8. 0 processo de formação do capitalismo foi estudado, sobretudo em Wirtschaftgechichte - utilizado aqui WEBER, 1968 Também relevantes neste sentido são $A$ ética protestante e o espírito do capitalismo, e Economia Sociedade. Mas, considere-se que mesmo em trabalhos de natureza eminentemente teóricometodológicos esta preocupação também existe.

9. Traduzido para o português quem conduziu a uma melhor compreensão do lugar ocupado pela economia na história grega antiga. Apesar de ter os seus trabalhos em economia antiga, assim como em história antiga geral, negligenciados. A sua obra foi pouco analisada pelos historiadores até que Finley recolocou Weber no centro do debate sobre a economia antiga (JOLY, 1999). Foi uma redescoberta progressiva: The ancient economy (1973), The Ancient City: from Fustel de Coulanges to Max Weber and beyond (1977) ${ }^{7}$, Max Weber and the Greek City State (1985) até o epílogo à $2^{\text {a }}$ edição do The Ancient Economy (1985). Esta duração da não recepção de Weber fez com que os especialistas de economia antiga tivessem tido a tendência de resumir a sua contribuição em alguns conceitos e teorias e o tenham lido, em geral, através de Finley ou de Karl Polanyi (BRUHNS, 1996, p. 1274).

Segundo o Prof. Joly, Weber não pretendia uma teoria entre essas duas - a economia centrada no oikos ou a economia de mercado - mas queria entender o processo de evolução do capitalismo, o que, de fato, foi uma preocupação constante em sua produção intelectual ${ }^{8}$. Weber percebeu limitações nos trabalhos de Bücher e de Meyer, principalmente em ordem metodológica, o que fez com que a sua interpretação sobre a economia antiga estivesse muito ligada a uma discussão sobre uma metodologia para a história da economia antiga, assim, deve-se ler a obra de Weber sobre a antiguidade no contexto do conjunto de sua obra geral (BRUHNS, 1996).

Em 1904 publicou Objetividade do conhecimento na ciência social e na ciência política, onde dissertou sobre a epistemologia do "tipo ideal", "instrumento analitico que considerava como um dos mais capazes de proporcionar resultados significativos no campo da teoria do conhecimento" (JOLY, 1999, p. 11). Em 1906 publicou Estudos críticos sobre a lógica das ciências da cultura, onde realizou uma crítica à metodologia da História que havia sido defendida por Meyer, sobretudo a noção de causalidade histórica. Aí está estabelecida a base metodológica em que Weber se apoiaria na sua proposição de uma interpretação da economia antiga.

Especificamente sobre a economia antiga, Weber publicou a já citada tese de 1891; em 1896 escreveu Die sozialen Gründe des Untergangs der antiken Kultur, um ensaio sobre as causas do declínio da cultura antiga; em 1897 Die Agrarverhälnesie des Altertums (2 ${ }^{\mathrm{a}}$ ed. De 1909); e, entre 1911 e 1913 o estudo Die Stadt (A cidade), publicado em 1921, com discussões acerca das particularidades da cidade antiga. Em todas se podem perceber o posicionamento metodológico de Weber frente aos debatedores.

As objeções metodológicas de Weber a Bücher e Meyer são desenvolvidas a partir da seguinte questão: uma história econômica da Antiguidade deve servir-se de categorias particulares, não aplicáveis a uma história medieval ou moderna, ou, pelo contrário, pode recorrer a conceitos modernos? (JOLY, 1999, p. 11)

Assim, percebe-se que a colocação de Weber no debate, além de estar ligada com suas preocupações com a origem do capitalismo, está inserida nas concepções metodológicas desenvolvidas ao longo de sua vida. Weber formula um modelo de economia antiga na forma de conceitos classificatórios - como de capitalismo político ou de cidade de consumo.

Com relação a Bücher, Weber foi favorável à proximidade de sua teoria com a ideia do "tipo ideal" - um pressuposto metodológico que, segundo Weber, deve estar subjacente a qualquer pesquisa histórica mas critica a visão homogênea que Bücher construiu sobre a antiguidade, já que o conceito de economia de oikos abarcaria apenas alguns períodos da história grega. Com relação à Meyer, Weber censura-lhe pela incongruência do quadro conceitual frente à documentação (JOLY, 1999), assim como Bücher, em sua resposta à Meyer, havia já percebido.

\section{Cidade de consumidores}

Weber, então, rejeitou a alternativa modernismo/primitivismo, na qual se encerrava o debate (apesar de ter recorrido a ela, como se viu acima). "Procurava definir a cidade grega antiga por oposição à cidade medieval. A cidade grega era [...] uma cidade de consumidores, ao passo que a cidade medieval era uma cidade de produtores" (AUSTIN, VIDAL-NAQUET, 1986, p. 19). A cidade antiga era, antes de tudo, uma associação política, que visava 
o abastecimento de itens básicos à sobrevivência e a guerra. Percebe-se a relevância que Weber deu à guerra na cidade grega, para ele "a base da democratização é, em toda, de natureza puramente militar [...] sendo decisivo o triunfo da disciplina militar sobre a luta de tipo heroico" (WEBER, 1968, p. 287), diz ainda que

A antiga democracia municipal é uma corporação política. Tem, obviamente, certos interesses de tipo lucrativo, que aparecem monopolizados; mas trata-se de interesse de caráter bélico [...] Deste modo, explica-se que, na Antiguidade, um afã de lucro se oriente no sentido de ganhos bélicos e até outros benefícios, que pudessem ser adquiridos por vias puramente políticas (WEBER, 1968, p. 292-293).

0 comportamento econômico das cidades gregas visava sempre o abastecimento do Estado e dos cidadãos, e nunca uma política de exportação que procurasse escoar, de forma vantajosa, a produção da cidade. A cidade tem em conta os interesses econômicos dos cidadãos enquanto consumidores, não como produtores. Deslocou-se assim, o debate das formas e extensão da atividade econômica para as relações entre a economia e a vida política da cidade grega. Ideia que, mais tarde, Hasebroek desenvolveu afirmando que não tinha como haver política econômica na cidade grega em sentido moderno, "porque não existia comércio ou indústria nacional nas cidades, devido ao papel considerável desempenhado na atividade econômica pelos estrangeiros, livres ou escravos, que não tinham, por definição, acesso algum à política da cidade" (AUSTIN, VIDAL-NAQUET, 1986, p. 19).

Mas deve-se tomar cuidado com a utilização dos conceitos weberianos. A cidade antiga como centro de consumo, oposta à cidade medieval como centro de produção são tipos ideais, portanto, instrumentos e não objetos de pesquisa (BRUHNS, 1996). Assim, considere-se que a cidade de consumidores não faz parte da construção ideal-típica da cidade antiga, já que sobre a cidade medieval, Weber definiu o tipo da cidade marítima mediterrânea com preponderância comercial, um tipo próximo ao da cidade antiga, definiu também as pequenas cidades camponesas, próximas das pequenas cidades antigas, ficando somente o tipo das cidades industriais distante do tipo da cidade antiga. Também não se deve confundir a oposição entre cidade de consumidores e cidade de produtores como uma oposição entre cidade e campo, pois os interesses dos consumidores podem ser defendidos por camponeses, que não tem interesse em lucro - Weber não os opõe! Weber caracteriza a cidade antiga como uma cidade de consumidores na medida em que o demos não se orienta sobre atividades produtoras pacíficas e sobre a empresa econômica nacional, "desde que esta construção não é mais considerada como um enunciado geral sobre a cidade antiga, o conceito de cidade de consumidores toma proporções mais modestas e volta a ser operacional para uma análise das políticas econômicas urbanas" (BRUHNS, 1996, p. 1279).

\section{Capitalismo político}

Outro conceito weberiano útil aos estudos sobre a economia na cidade grega antiga é o de capitalismo político. 0s tipos de capitalismo aplicados à antiguidade são os "de guerra", "de saque", o "capitalismo aventureiro" e mesmo o "capitalismo agrário romano", analisado desde 1891. São todos eles capitalismo político. Não se deve confundir com as teorias dos períodos econômicos (BRUHNS, 1996), comum aos economistas da Escola Historicista Alemã de Economia; este é um instrumento de análise que permite determinar a natureza das chances de ganho, como pressupõe a própria terminologia.

Segundo Bruhns, para apresentar formas de organização econômica na antiguidade e na contemporaneidade, Weber utiliza-se de duas variáveis, 1) a forma de atividade econômica (gestão doméstica ou atividade para ganho), assim como a forma de utilização dos bens que disso tenha em consequência - "ele opõe duas atitudes econômicas não a partir de necessidades, mas de estratégias" (BRUHNS, 1996, p. 1280) e a segunda variável é 2) a forma de exploração - se econômica ou política - o que leva à distinção entre duas formas de acumulação de capital: "pela utilização das chances de poder 
(ou de ganho) políticos; pela utilização das chances de poder (ou de ganho) econômicos (como no caso da utilização de uma força de trabalho formalmente livre para a produção de bens para o mercado)" (BRUHNS, 1996, p. 1280). A distinção entre capitalismo político e capitalismo econômico, assim, não é, em Weber, uma distinção entre capitalismo antigo e capitalismo moderno, visto as categorias de capitalismo rendeiro e empreendedor permitirem diferenciações suplementares.

Em sua busca por entender a origem do capitalismo moderno, Weber se preocupou com os graus de racionalidade em diferentes épocas e as condições institucionais e sociais que o permitiram. Segundo Weber,

Decisivamente, o capitalismo surgiu através da empresa permanente e racional, da contabilidade racional, da técnica racional e do direito racional. A tudo isto se deve ainda adicionar a ideologia racional, a racionalização da vida, a ética racional na economia (WEBER, 1968, p. 310).

Isto permite diferenciar as configurações e os usos do capital, permitindo uma análise mais apurada da economia antiga do que aquela habitualmente praticada na oposição entre capitalismo político antigo e capitalismo econômico moderno - o que está claramente assimilado à ideia de estágios de desenvolvimento econômico (BRUHNS, 1996).

\section{Ética e economia}

Por fim, uma última contribuição de Weber aos estudos de economia antiga: a noção de que a prática econômica era conduzida por uma ética ligada a polis, isto na medida em que Weber pretende "examinar a relação da economia [...] com a sociedade, o que significa, neste caso, com as formas estruturais gerais de comunidades humanas" (WEBER, 1991, p. 243), a sociedade, a comunidade política por excelência, na Grécia clássica, era a polis.

A preocupação com a ética econômica sempre esteve presente em suas reflexões, como em seu famoso trabalho Die protestantische Ethik und der
'Geist' des Kapitalismus', de 1904-1905. Para ele, a ética econômica não se constitui como doutrina econômica, mas como adaptação e racionalização das condutas de vida, o que implica na associação entre "economia e sociedade". No que concerne à antiguidade, há apenas referências sobre a ligação entre ética econômica, religião e comportamento econômico.

Weber afirmou que a principal diferença entre o capitalismo moderno e o capitalismo antigo não se encontrava no desejo pelo lucro, diz ele que " $a$ crença de que a atual época racionalista e capitalista possui um estímulo mais forte do que outras é uma ideia infantil" (WEBER, 1968, p. 311), assim, o capitalismo moderno não seria o resultado de uma busca pelo ganho, mas sim o da passagem para uma racionalização da vida com este fim, e que não repousa unicamente sobre fatores econômicos. Weber chama a atenção sobre o fator religioso, mas ele não é o único: interessante no estudo da cidade medieval e antiga é identificar outros fatores, como o geográfico, os políticos, os militares, os institucionais, os jurídicos (BRUHNS, 1996). Mas, a ligação de Weber entre a ética religiosa e a conduta de vida econômica não pode ser considerada como uma relação causal, nem unilateral, e "transposto para a antiguidade, a questão das condutas de vida e de sua racionalização não pode, então, se resumir a uma interrogação sobre as doutrinas ou as ideologias concernentes ao ganho ou ao trabalho" (BRUHNS, 1999, p. 1283), mas à relação entre ela e a sociedade.

Com isto pode-se concluir: Weber reconheceu um problema metodológico na história econômica da antiguidade, a tendência geral de se aplicar modelos sobre uma realidade empírica. Sabe-se que ele valoriza, acima de tudo, os conceitos, acima da coleção de fatos, mas reconhece a problemática de não se definir o que é ideal do que é exemplar. E, mais do que uma contribuição teórico-metodológica, Weber contribuiu para o entendimento da natureza da economia grega antiga no nível das instituições e dos fatos (o que enriquece os conhecimentos sobre a época). 


\section{REFERÊNCIAS BIBLIOGRÁFICAS}

AUSTIN, Michel, VIDAL-NAQUET, Pierre (1986). Economia e Sociedade na Grécia Antiga. Lisboa: Edições 70.

BRUHNS, Hinnerk (1996). Max Weber: l'économie et l'histoire. Annales HSS. Paris.

DESCAT, Raymond (1995). L'économie antique et la cité grecque: un modele em question. Annales HSS. Paris.

JOLY, Fábio Duarte (1999). Capitalismo e burocracia: economia e política nas Relações Agrárias na Antiguidade de Max Weber. Revista de História da USP. São Paulo, n. 140.
WEBER, Max (1991). Economia e Sociedade. V.1. Brasília, Ed. UNB.

(1968). História Geral da Economia. São Paulo, Editora Mestre Jou.

(1958). The city.Tradução para inglês de Don Martindale e Gertrud Neuwirth. Illinois, The Free Press.

WILL, Édouard (1954). Trois quarts de siècles de recherches sur l'économie grecque antique. Annales ESC. Paris.

Recebido em abril de 2011. Aprovado em maio de 2011. 